\title{
Endocrine abnormalities in lithium toxicity
}

\author{
Authors: Gabriella Shanks, ${ }^{A}$ Vinita Mishra ${ }^{B}$ and Stanka Nikolova ${ }^{C}$
}

Lithium toxicity can manifest as a variety of biochemical abnormalities. This case report describes a patient presenting to the emergency department with neuropsychiatric symptoms on a background of bipolar disorder, for which she was prescribed lithium for $\mathbf{2 6}$ years previously. Cases of lithium toxicity are rare but can be severe and this case report demonstrates to clinicians that they must be thorough in investigating patients with lithium toxicity, as there are many potential abnormalities that can manifest concurrently.

KEYWORDS: Acute, biochemical, endocrine, lithium, toxicity

\section{Case presentation}

A 58-year-old female was admitted to the accident and emergency department after being found in a confused state at home, with complaints of progressive leg weakness, poor appetite, slurred speech and worsening anxiety and depression. Her background consisted of longstanding bipolar affective disorder, stable with 26 years of lithium therapy (lithium carbonate modified release $400 \mathrm{mg}$ three times per day). She had recently restarted lithium after it had been discontinued for 3 weeks. Her drug history also included chlorpromazine and cephalexin (prescribed in hospital for a presumed urinary tract infection). Clinical examination was unremarkable. Baseline investigations are shown in Table 1.

\section{Diagnosis}

Her blood biochemistry showed a moderate hypernatraemia (with a raised urea) suggesting dehydration, hypercalcaemia with hyperparathyroidism, hyperthyroidism and lithium levels above the therapeutic range (lithium levels prior to this admission had always been therapeutic). Other differential diagnoses include primary hyperparathyroidism, hyperthyroidism, dehydration due to poor oral intake and diabetes insipidus. The likely diagnosis is lithium-induced nephrogenic diabetes insipidus causing hypernatraemia, hyperparathyroidism and hyperthyroidism.

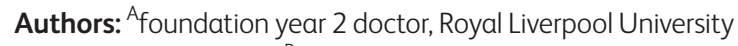
Hospital, Liverpool, UK; ${ }^{\text {B }}$ consultant chemical pathologist, Royal


Liverpool and Broadgreen University Hospital NHS Trust, Liverpool, UK
Table 1. Results of baseline investigations

\begin{tabular}{lll} 
Analyte & Result & Reference range \\
Sodium & $151 \mathrm{mmol} / \mathrm{L}$ & $133-146$ \\
Potassium & $3.7 \mathrm{mmol} / \mathrm{L}$ & $3.5-5.3$ \\
Urea & $8.5 \mathrm{mmol} / \mathrm{L}$ & $2.5-7.8$ \\
Creatinine & $70 \mathrm{mmol} / \mathrm{L}$ & $50-130$ \\
Adjusted calcium & $3.46 \mathrm{mmol} / \mathrm{L}$ & $2.2-2.6$ \\
Bicarbonate & $28 \mathrm{mmol} / \mathrm{L}$ & $22-29$ \\
Glucose & $6.5 \mathrm{mmol} / \mathrm{L}$ & \\
C-reactive protein & $<5 \mathrm{mg} / \mathrm{L}$ & $<5$ \\
Haemoglobin & $11.8 \mathrm{~g} / \mathrm{dL}$ & \\
White blood cells & $15.110^{9} / \mathrm{L}$ & \\
Reticulocytes & $11.610^{9} / \mathrm{L}$ & \\
Plasma lithium level & $2.06 \mathrm{mmol} / \mathrm{L}$ & $0.4-1$ \\
Parathyroid hormone & $8.8 \mathrm{pmol} / \mathrm{L}$ & $1.1-6.9$ \\
Thyroid-stimulating hormone & $<0.05 \mathrm{mU} / \mathrm{L}$ & \\
Free T4 & $80.8 \mathrm{pmol} / \mathrm{L}$ & \\
Free T3 & $13.4 \mathrm{pmol} / \mathrm{L}$, & \\
Thyroid-receptor antibodies & $60 \mathrm{U} / \mathrm{L}$ \\
Thyroid peroxidase antibodies & $<10 \mathrm{IU} / \mathrm{L}$ \\
Urine dipstick & ++1 eucocytes \\
\hline T3 =triiodothyronine; T4 = thyroxine & $++\mathrm{ketones}$ \\
\hline
\end{tabular}

\section{Initial management and prognosis}

To manage this patient's hypercalcaemia and hypernatremia, 3 litres of $0.9 \%$ sodium chloride were infused over 24 hours to rehydrate the patient, followed by zolendronic acid $(4 \mathrm{mg}$ in $500 \mathrm{~mL}$ of sodium chloride $0.9 \%$ intravenously) to correct the raised serum corrected calcium. 5\% dextrose was then administered intravenously to correct the hypernatremia. The hyperthyroidism was treated with propranolol $40 \mathrm{mg}$ and carbimazole $40 \mathrm{mg}$ once daily. Lithium was discontinued.

\section{Case progression and outcome}

Unfortunately the patient clinically deteriorated, spiking fevers up to $38.5^{\circ} \mathrm{C}$. White blood cells remained elevated; however, $\mathrm{C}$-reactive protein remained normal. Infection was suspected 
but never localised. Despite fluid resuscitation initially with sodium chloride $0.9 \%$ to correct the hypercalcaemia and then dextrose $5 \%$ to correct the hypernatraemia, the sodium level gradually creeped up to $172 \mathrm{mmol} / \mathrm{L}$ by day 4 . She became increasingly confused and agitated with a fluctuating Glasgow Coma Score (GCS) between 11 and 3. Computerised tomography head and X-ray chest were both unremarkable. She was started on tazobactam/piperacillin $4.5 \mathrm{~g}$ three times daily and hydrocortisone $100 \mathrm{mg}$ three times daily. On the 9th day after admission the patient developed hypocalcaemia and hypophosphataemia and she was found to be vitamin D deficient; she was commenced on alfacalcidol $250 \mathrm{ng}$ daily and calcichew D3 forte twice daily. Unfortunately, the patient developed flaccid quadraparesis, inability to swallow and inability to phonate. A provisional diagnosis of GuillainBarré syndrome was made, with other differentials including myasthenia gravis and thyrotoxic myopathy. The condition of the patient warranted admission into the intensive therapy unit on the 10th day post admission. Clinically the patient still had a fluctuating GCS with unresponsive episodes, remaining pyrexic and tachycardic despite intravenous antibiotics. Antithyroid medication was adjusted to prophylthiouracil $200 \mathrm{mg}$ and propranolol $80 \mathrm{mg}$ both twice daily; Lugol iodine $0.1 \mathrm{~mL}$ twice daily was also introduced. Despite intense rehydration with $5 \%$ dextrose (on average 6 litres per day) the sodium level remained elevated at $166 \mathrm{mmol} / \mathrm{L}$ (Table 2). The urine to serum osmolality ratio was reduced to 0.76 , which supported the diagnosis of nephrogenic diabetes insipidus. The patient's condition did not allow for a water deprivation test to be carried out in order to confirm nephrogenic diabetes insipidus. Amiloride $5 \mathrm{mg}$ daily was started. This engendered a positive response and sodium was seen to be in the normal range before amiloride was discontinued.

Further studies were carried out to investigate her neurological symptoms. Magnetic resonance imaging electroencephalography, electromyography and nerve conduction studies found marked cerebral atrophy and myopathy. These results did not support Guillain-Barré syndrome. Cerebrospinal fluid analysis found oligoclonal bands type 2 . The patient was started on intravenous immunoglobulin therapy on day 14 post admission and consequently the muscle paresis and weakness improved substantially in the next 3 weeks.

Improvements in thyroid functions were noted by the 28th day post admission; at this point, the doses of propylthiouracil and propranolol were reduced to $100 \mathrm{mg}$ three times a day and $40 \mathrm{mg}$ twice a day, respectively. Serum adjusted calcium and parathyroid hormone returned to the normal range by the 45 th day post admission.

She was discharged to a neurology tertiary centre for further rehabilitation. The exact nature of the neurological disorder remained unclear on discharge.

\section{Discussion}

Lithium predominantly causes hypothyroidism and lithiuminduced hyperthyroidism is rare; estimates in studies range from $0.1-1.7 \%$. Aetiology includes diffuse goitre, toxic multinodular goitre and painless thyroiditis. Lithium can potentially directly be toxic to the thyroid gland in a similar mechanism to amiodarone by way of ultra-structural lysosomal and mitochondrial damage. ${ }^{1}$ Lithium-induced hyperthyroidism can be managed with antithyroid medications as described; steroids may also be used.

The patient's bloods initially suggested dehydration; however, the hypernatraemia did not respond to rehydration and a diagnosis of nephrogenic diabetes insipidus, a wellknown effect of lithium toxicity, was established instead. The mechanism is impairment of antidiuretic hormone-stimulatory effect on adenylate cyclase in the distal renal tubule, with reduced production of cAMP, which, in turn, decreases the diffusion of water through pores in the cell membrane of the collecting tubules. This results in an inability to concentrate the urine. Amiloride is beneficial here as it blocks uptake of lithium through epithelial sodium channels in the collecting duct and has been shown to clinically improve nephrogenic diabetes insipidus. $^{2}$

Table 2. Results of subsequent investigations during inpatient stay

\begin{tabular}{|c|c|c|c|c|c|c|c|c|c|c|}
\hline Analyte & Reference range & Day -3 & Day 0 (admission) & Day 4 & Day 7 & Day 9 & Day 13 & Day 17 & Day28 & $\begin{array}{l}\text { Day } 45 \\
\text { (discharge) }\end{array}$ \\
\hline Lithium & $0.40-1.00 \mathrm{mmol} / \mathrm{L}$ & 0.94 & 2.06 & 0.30 & & & & & & \\
\hline $\mathrm{Na}$ & $133-146 \mathrm{mmol} / \mathrm{L}$ & 140 & 151 & 172 & & 169 & 160 & 141 & 139 & 139 \\
\hline K & $3.5-5.3 \mathrm{mmol} / \mathrm{L}$ & 4.1 & 3.7 & 3.8 & & 3.2 & 3.8 & 3.9 & 4.7 & 5.1 \\
\hline $\mathrm{HCO}_{3}$ & $22-29 \mathrm{mmol} / \mathrm{L}$ & 26 & 28 & 24 & & 20 & 25 & 25 & 26 & 23 \\
\hline Urea & $2.5-7.8 \mathrm{mmol} / \mathrm{L}$ & 5.1 & 8.5 & 5.6 & & 5.8 & 6.5 & 5.1 & 3.3 & 2.9 \\
\hline Creat & $50-130 \mu \mathrm{mol} / \mathrm{L}$ & 62 & 70 & 61 & & 46 & 38 & 29 & 28 & 39 \\
\hline $\mathrm{ACa}$ & $2.20-2.60 \mathrm{mmol} / \mathrm{L}$ & & 3.41 & 2.85 & 2.19 & 1.93 & 2.28 & 2.34 & 2.36 & 2.51 \\
\hline IPhosph & $0.80-1.50 \mathrm{mmol} / \mathrm{L}$ & & 1.00 & 0.74 & 0.54 & & 0.65 & 0.80 & 1.00 & \\
\hline PTH & $1.1-6.9 \mathrm{pmol} / \mathrm{L}$ & & 8.8 & & 40.2 & & & & & 6.5 \\
\hline TSH & $0.30-6.0 \mathrm{mU} / \mathrm{L}$ & & $<0.05$ & $<0.05$ & & $<0.05$ & & & $<0.05$ & \\
\hline FT4 & $10.0-22.0 \mathrm{pmol} / \mathrm{L}$ & & 80.8 & 89.9 & & 89.9 & & & 22 & \\
\hline
\end{tabular}


Hyperparathyroidism is a known side effect of lithium toxicity, primarily with chronic toxicity. ${ }^{3}$ Unfortunately, adjusted calcium and parathyroid hormone had not been monitored prior to this admission. There is debate over whether lithium initiates hyperparathyroidism or promotes an underlying subclinical state of hyperparathyroidism. After discontinuation of lithium, the hypercalcaemia may not always resolve; thus, intense hydration with saline, intravenous bisphosphonates and even parathyroidectomy may be necessary in some cases. ${ }^{4}$ Intense hydration and intravenous zolendronic acid resolved the hypercalcaemia; however, this unmasked a vitamin $\mathrm{D}$ deficiency that resulted in hypocalcaemia.

\section{Conclusions}

Lithium toxicity, although rarely seen, can cause serious adverse effects and serious endocrine abnormalities in particular. ${ }^{5}$ This case discusses multiple endocrine abnormalities suggesting that clinicians should remain vigilant when investigating cases of possible lithium toxicity. In such cases all possible adverse effects of lithium on the endocrine system should be thoroughly investigated, especially if unexplained clinical symptoms are present.

\section{Conflicts of interest}

The authors have no conflicts of interest to declare.

\section{Acknowledgements}

Written consent has been obtained from the patient for publication of the clinical details in this article.

\section{References}

1 Bocchetta A, Loviselli A. Lithium treatment and thyroid abnormalities. Clinic Pract Epidemol Ment Health 2006;2:23-8.

2 Stone K. Lithium-induced nephrogenic diabetes insipidus. J Am Board Fam Med 1999;12:43-7.

3 Szalat A, Mazeh H, Freund HR. Lithium-associated hyperparathyroidism: report of four cases and review of the literature. Eur J Endocrinol 2009;160;317-23.

4 Brown EM. Lithium induces abnormal calcium-regulated PTH release in dispersed bovine parathyroid cells. J Clin Endocrinol Metab 1981;52:1046-8.

5 McKnight RF, Adida M, Budge $\mathrm{K}$ et al. Lithium toxicity profile: a systematic review and meta-analysis. Lancet 2012;379:721-8.

Address for correspondence: Dr Gabriella Shanks, Department of Clinical Biochemistry and Metabolic Medicine, Royal Liverpool and Broadgreen University Hospital NHS Trust, Liverpool L7 8XP, UK.

Email: gabriella.shanks@doctors.org.uk

\title{
An unusual case of refractory status epilepticus in a young lady: anti-NMDA receptor encephalitis
}

\author{
Authors: Ching Soong Khoo, ${ }^{A}$ Nurul Husna Zulkifli ${ }^{B}$ and Siti Soraya Ab Rahman ${ }^{C}$
}

\begin{abstract}
We describe a case of a young lady with anti-NMDA ( $N$-methylD-aspartate) receptor encephalitis, who initially presented with status epilepticus. Her seizures and orofacial dyskinesia were refractory to four anticonvulsants. She received intravenous immunoglobulin and a left ovarian tumour (an associated feature) was resected. However, her outcome was poor because of delayed treatment, autonomic dysfunction and complications of prolonged hospitalisation. This case highlights the importance of an early recognition of this rare but increasingly recognised disease.
\end{abstract}

KEYWORDS: Status epilepticus, anti-NMDA receptor encephalitis

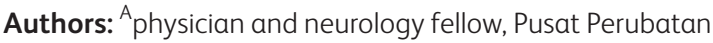
Universiti Kebangsaan Malaysia, Cheras, Kuala Lumpur, Malaysia; ${ }^{B}$ medical officer, Hospital Ampang, Selangor, Malaysia; ${ }^{C}$ radiologist and medical lecturer, Islamic Science University of Malaysia, Pandan Indah, Kuala Lumpur, Malaysia

\section{Case presentation}

A 21-year-old woman with no past medical history presented to the emergency department with a 5-day history of bitemporal headaches and fever and altered behaviour (she had been talking to herself and forgetful) for the past 3 days. Otherwise, there were no symptoms suggestive of urinary tract infection, upper respiratory tract infection and gastroenteritis. She denied a history of head trauma, febrile seizures or family history of epilepsy. Her physical examination was unremarkable. Her presenting vitals were as follows: blood pressure 120/78 $\mathrm{mmHg}$, heart rate $72 \mathrm{bpm}$, temperature $37^{\circ} \mathrm{C}$ and $\mathrm{SpO}_{2} 98 \%$ on room air. However, she developed convulsive status epilepticus the day after admission and was subsequently intubated.

Initial blood results revealed leucocytosis (white cell count $\left.18.9 \times 10^{9}\right)$, mild hypokalaemia $(3.3 \mathrm{mmol} / \mathrm{L})$ and an erythrocyte sedimentation rate of $80 \mathrm{~mm} /$ hour. Other investigations, including random blood glucose, haemoglobin, platelet, electrolytes, 